\title{
Respiratory immunohistochemical study in rats exposed to cigarette smoke and alcohol ${ }^{1}$
}

\author{
Karla Luciana Magnani', Daniele Cristina Cataneo" ${ }^{I I}$, Maria Aparecida Custódio Domingues ${ }^{\text {III }}$, Erica Nishida Hasimoto ${ }^{\mathrm{I}}$, Thaiane \\ Cristine Evaristo', Antônio José Maria Cataneo ${ }^{\mathrm{IV}}$
}

DOI: http://dx.doi.org/10.1590/S0102-865020150030000003

IFellow PhD degree, Postgraduate Program in General Basis of Surgery, Botucatu School of Medicine, State university of Sao Paulo (UNESP), Brazil. Acquisition and interpretation of data, manuscript writing.

IIPhD, Associate Professor, Division of Thoracic Surgery, UNESP, Sao Paulo-SP, Brazil. Conception and design of the study.

IIIPhD, Assistant Professor, Department of Pathology, UNESP, Sao Paulo-SP, Brazil. Acquisition and interpretation of data.

${ }^{\text {IV }} \mathrm{PhD}$, Head and Full Professor, Division of Thoracic Surgery, UNESP, Sao Paulo-SP, Brazil. Conception, design, intellectual and scientific content of the study.

\begin{abstract}
PURPOSE: To investigate the effects of exposure to cigarette and alcohol on immunohistochemical disorders caused by these attacks to respiratory system of rats.

METHODS: Sixty male Wistar rats in four groups: control, cigarette smoke, alcohol and cigarette smoke + alcohol during 260 days. Immunohistochemistry was performed by researching survivin and protein P53 expressions and apoptotic index in parenchymal lung and trachea using TUNEL technique.

RESULTS: There was body growth impairment in all experimental groups. Both smoker groups animals had higher trachea survivin expression and bronchial higher apoptotic index. The trachea apoptotic index was also higher in the cigarette smoke group as well as in the alveoli in the cigarette smoke + alcohol group. The three experimental groups showed negative immunoexpression for P53.

CONCLUSIONS: this model resulted in immunohistochemical changes caused mainly by exposure to cigarette smoke. There was a synergistic action between alcohol and tobacco in the growth impairment in animals as well as in the cellular apoptotic index. The positive immunoexpression for tracheal survivin in animals from both groups exposed to tobacco smoke and associated with a negative P53 immunoexpression suggests that despite the aggression, carcinogenesis has not happened yet. In addition, the bronchial higher apoptotic index in smokers may be responsible for emphysema.
\end{abstract}

Key words: Smoking. Alcoholism. Emphysema. Apoptosis. Rats. 


\section{Introduction}

We already noted by electron microscopy, the morphological changes in the lungs of rats exposed to tobacco and alcohol ${ }^{1}$. Concomitant use of these too drugs has been considered a risk factor for malignancies development in different organs, being very important in airway cancer. It is generally understood as a final result of uncontrolled growth that occurs in respiratory epithelium cells. This lack is seen as genetic modification that would alter the proliferative and regulatory activities of these cells. So, the study of apoptosis marker proteins such as P53, survivin and apoptotic cells disclosure becomes very important. Most cancers present p53 gene mutations or defaults in its regulation. There are strong evidences of P53 involvement in the suppressing tumorigenesis by DNA repair in the G1 mitoses phase. When DNA damages are not liable to be repaired, the apoptosis activation occurs. Mutations in the p53 gene result in G1 lack checkpoint, allowing damaged cells to progress to $\mathrm{S}$ phase neither repairing injuries nor developing apoptosis. Despite being an apoptosis enzyme inhibitor, Survivin inhibits cell death in vitro by extrinsic and intrinsic apoptosis and is involved in mitotic spindle organization and cytokines regulation ${ }^{2}$. Apoptosis suppression contributes to carcinogenesis by different mechanisms, including increasing the abnormal cells lifetime, thereby facilitating mutant genes accumulation and promoting immune cytotoxic resistance ${ }^{2}$. The apoptotic index elevation that occurs in cancer may also be present in pulmonary emphysema due to alveolar wall cells apoptosis.

In relation to alcohol consumption and the mechanisms involved in lung tissue apoptosis, most studies refer the pathophysiological mechanism and treatment of acute respiratory distress syndrome ${ }^{3,4}$. Among the pathophysiological mechanisms involved, we can observe the reduction in surfactant production, alveolar-capillary membrane integrity loss and increased sensitivity to apoptosis of type II pneumocytes induced by cytokines in vitro and in vivo. The aim of this study was to investigate the deleterious effects of alcohol and tobacco chronic use produced in respiratory tract of rats by immunohistochemical evaluations.

\section{Methods}

All procedures were performed in strict accordance to US guidelines National Research Council's “Guide for care and use of laboratory animal" (NRC publication - 1996) and were approved by local "Ethical Committee for Animal Research".

The study comprised 60 adult male Wistar rats weighing between 180-200g, from Central Animal Laboratory of UNESP.
Rats were kept in Animal Laboratory of Surgery and Surgical Technique, in controlled temperature $\left(23 \pm 2{ }^{\circ} \mathrm{C}\right)$ and humidity room $(60 \pm 5 \%)$, with 12 hour light-dark period. The animals were housed in polyurethane cages, 5 rats in each cage, and were weighted once a week (Mettler Toledo ${ }^{\circledR}$ : Spider 2). They were given standard commercial diet (Purina ${ }^{\circledR}$, Brazil) and water $a d$ libitum during acclimation period (seven days) before the experiment started.

After acclimation period, animals were randomly distributed into four groups as follows: control, alcohol, cigarette smoke, alcohol + cigarette smoke. Next, the following protocols were initiated: exposure to ethanol and tobacco smoke for 260 days, in which the concentration of ethanol (Pirassununga 51 - Müller Liquor Industry, Ltd. Piracicaba-SP, Brazil) in the water provided for the rats, was progressively increased by $10^{\circ} \mathrm{GL}$ per week to $30^{\circ} \mathrm{GL}$ and then maintained until the end of the experimental period. Alcohol concentration was measured with an alcoholometer. Exposure to cigarette smoke was performed using a method previously standardized in our laboratory experiment ${ }^{5}$. The rats, five each time, were placed in a clear chamber connected to the smoking device with a volume of nearly $95 \times 80 \times 65 \mathrm{~cm}$. Smoke puffs were drawn from the cigarette by vacuum and then blown inside the chamber for 30 minutes. During the first week, the smoke was released at a rate of five cigarettes/30 minutes/day (seven days/ week), in the morning. From the second week on, the number of cigarettes was increased to a rate of 10 cigarettes/30 minutes, until the end of the period of the study. Commercial cigarette composition was as follows: $1.1 \mathrm{mg}$ of nicotine, $14 \mathrm{mg}$ of tar, and $15 \mathrm{mg}$ of carbon monoxide.

After experiment conclusion (260 days), the animals were kept in fasting for 12 hours and anesthetized with intraperitoneal sodium pentobarbital $(30 \mathrm{mg} / \mathrm{kg})$. Then the animals were weighed and measured its length. Was subsequently calculated their body mass index (weight/length ${ }^{2}$ ). Then a cervical, thoracic and abdominal trichotomy, iodine alcohol antisepsis (2\%) and median xifopubic laparotomy were carried out. After a complete inferior vena cava and abdominal aorta section were performed for animals sacrifice by exsanguinations.

\section{Survivin and P53}

The lungs and trachea paraffin sections of seven randomly selected animals from each group were submitted to immunohistochemical reaction using primary antibodies: P53 and Survivin. The immunohistochemical reaction was performed 
by Avidin Biotin peroxidase method, according to Hsu et al. ${ }^{6}$. The slides were mounted with coverslips and Permont 24 x 32 (Knittel) and read using a biocular optical microscope (NIKON) as well. The appearance of brown nuclear reactivity for P53 and cytoplasmic for survivin was considered as a standard of positivity. Further details of apoptosis markers are described in Table 1.

TABLE 1 - Description of cell proliferation markers studied.

\begin{tabular}{lccccc}
\hline Antibodies & $\begin{array}{c}\text { Monoclonal/ } \\
\text { policlonal }\end{array}$ & $\begin{array}{c}\text { Business/ } \\
\text { origin country }\end{array}$ & Dilution & $\begin{array}{c}\text { Retrieval antigen } \\
\text { method }\end{array}$ & $\begin{array}{c}\text { Secundary method } \\
\text { (each antibody staining pattern) }\end{array}$ \\
\hline $\begin{array}{l}\text { SURVIVIN } \\
\text { (clone 5E8) }\end{array}$ & Mouse Monoclonal & LabVision/USA & $1: 100$ & $\begin{array}{c}\text { Citric acid 0,21\% pH } \\
6.0 \text { in microwave oven } \\
\text { for 15'. }\end{array}$ & Kit LSAB (DAKO) \\
$\begin{array}{l}\text { P53 } \\
\text { (clone DO-7) }\end{array}$ & Mouse Monoclonal & DAKO/USA & $1: 150$ & $\begin{array}{c}\text { Citric acid 0,21\% pH } \\
\text { (D. } 0 \text { in microwave } \\
\text { oven for 15'. }\end{array}$ & Kit LSAB (DAKO) \\
\hline
\end{tabular}

\section{Apoptosis}

Concerning the in situ detection of apoptosis at the level of a single cell, we used a method of end-labeling mediated by deoxynucleotidyl transferase (TdT) (Boehringer Mannheim, Mannheim, Germany) ${ }^{7}$. Thick paraffin sections (4-6 mm) were layered on glass slides, deparaffinized with xylene, and rehydrated with graded dilutions of ethanol in water. The slides were washed 4 times with double-distilled water for two minutes and immersed in TdT buffer (Boehringer Mannheim). Then, TdT (0.3 U per microliter) and fluoresceinlabeled dUTP in TdT buffer were added to cover the section and the samples were incubated in a humid atmosphere at $37^{\circ} \mathrm{C}$ for 60 minutes. For negative controls, TdT was eliminated from the reaction mixture. Then, the sections were incubated with a specific antibody for fluorescein conjugated to peroxidase. The stains were visualized with a substrate system in which nuclei with DNA fragmentation stained brown. The reaction was finished by washing the sections twice in phosphate-buffered saline. The nuclei without DNA fragmentation stained blue as a result of counterstaining with hematoxylin. Positive controls consisted of rat prostatic gland after castration.

Apoptosis was assessed in 10 fields by the pointcounting technique in pulmonary area/group of seven animals, using a 100-point grid with a known area $\left(62500 \mathrm{~mm}^{2}\right.$ at a $\times 400$ magnification) attached to the ocular of the microscope. At x400 magnification, the pulmonary septal area in each field was calculated according to the number of points hitting connective tissue, as a proportion of the total grid area. Afterward, the number of positive cells within the pulmonary septal area was counted. The density of immune cells was determined as the number of positive cells in each field divided by the septal area. The final results were expressed as a percentage. Interobserver comparisons were performed in $20 \%$ of the slides by 2 observers. The coefficient of variation for the interobserver error of the cell count was $<5 \%$.

\section{Statistical analysis}

The results were expressed in means and standard deviation and statistically tested from factorial 2-way analysis (ANOVA). The post hoc Tukey multiple comparison test was used to investigate which of the means was different in order to assess the interaction between smoke cigarette exposure and alcohol ingestion. In order to studying the immunoreactivity survivin frequency was used chi-square distribution. All analyses were performed with SPSS statistical software (SPSS, Inc., Chicago, IL, USA). The statistical significance was set at a $\mathrm{p} \leq 0.05$.

\section{Results}

Fifty-seven animals out of the 60 ones that started the study completed it. One animal from each of the following groups: control, alcohol and cigarette smoke died.

\section{Animal growth}

Weight, length and BMI results are described in Table 2. It was observed that in weight and length variables all experimental groups had lower values than control group. Animals exposed to cigarette smoke had the most restricted growth in length, while those exposed to alcohol had a greater loss in weight. In relation to BMI, only alcohol group had lower values. 
TABLE 2 - Statistical analysis of growth variables: length $(\mathrm{cm})$, weight $(\mathrm{g})$ and body mass index $(\mathrm{kg} / \mathrm{m} 2)$ of the four groups of animals studied.

\begin{tabular}{lcccc}
\hline & Control(C) & Alcohol(A) & Tobacco(T) & $\begin{array}{c}\text { Alcool + } \\
\text { Tobacco } \\
\text { (AT) }\end{array}$ \\
\hline $\begin{array}{l}\text { Length } \\
\text { Weight }\end{array}$ & $28.2 \pm 0.9$ & $26.7 \pm 0,7$ & $25.6 \pm 1.8$ & $25.4 \pm 0.9$ \\
$\begin{array}{l}\text { Body } \\
\text { mass }\end{array}$ & $7.45 \pm 0.5$ & $6.33 \pm 0.5$ & $7.59 \pm 1.2$ & $6.73 \pm 0.4$ \\
index & & $452.6 \pm 50.0$ & $498.1 \pm 53.4$ & $433.9 \pm 43.7$ \\
\hline
\end{tabular}

Comparisons between groups - ANOVA (Tukey)

Length: C x A: $\mathrm{p}=0.007^{*} ; \mathrm{C} \times \mathrm{T}: \mathrm{p}=0.000^{*} \mathrm{C} \times \mathrm{AT}: \mathrm{p}=0.000^{*} ; \mathrm{A} \times \mathrm{T}: \mathrm{p}=0.13$; A $x$ AT: $p=0.013 * ;$ T x AT: $p=0.80$. Weight: $\mathrm{C} \times \mathrm{A}: \mathrm{p}=0.000^{*} ; \mathrm{C} \times \mathrm{T}: \mathrm{p}=0.000^{*} ; \mathrm{C}$ x AT: $p=0.000 *$; x T: $p=0.12$; $x$ AT: $p=0.78 ; \mathrm{T} \times \mathrm{AT}: \mathrm{p}=0.011^{*}$. Body mass Index: $\mathrm{C}$ x A: $\mathrm{p}=0.001 *$; $x$ T:p=0.96; $\mathrm{C} \times \mathrm{AT}: \mathrm{p}=0.05 ; \mathrm{A} \times \mathrm{T}$ : $\mathrm{p}=0.000 *$; $\times$ AT: $\mathrm{p}=0.46 ; \mathrm{T} \times \mathrm{AT}: \mathrm{p}=0.14$.

\section{Immunohistochemical markers}

\section{Protein 53 (P53)}

In all studied groups, P53 was negative in trachea, lungs, bronchi and bronchioles. The Figure 1 refers to an alcohol group animal, which like all other animals studied, showed negative immunoexpression for P53.

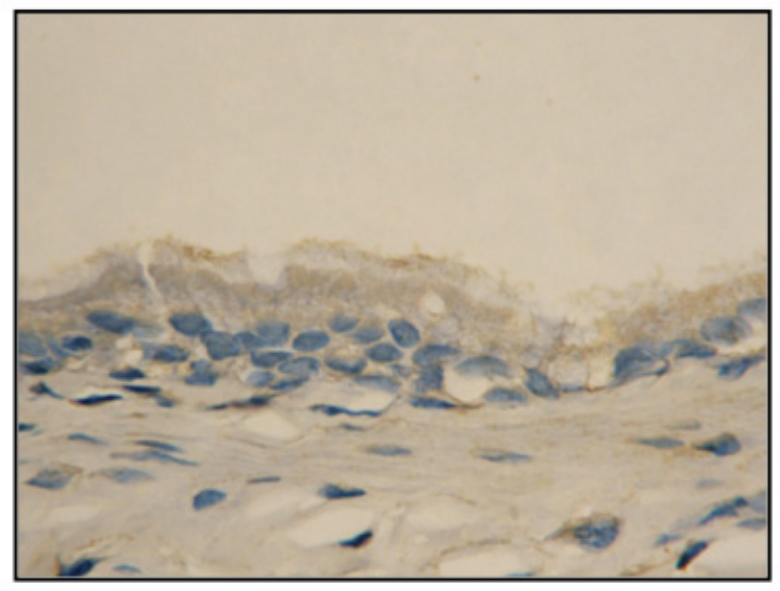

FIGURE 1 - Negative immunoreactivity in tracheal epithelium to P53 an alcohol animal group (x400 magnification).

\section{$\underline{\text { Survivin }}$}

The positive percentage for survivin in the trachea was $100 \%$ for the two groups exposed to cigarette smoke while in the other two groups was $0 \%(\mathrm{p}=0.000)$. The results in the lungs were $100 \%$ negative for all groups. Figure 2 represents the positive tracheal cytoplasmic reading in an alcohol + tobacco group animal.

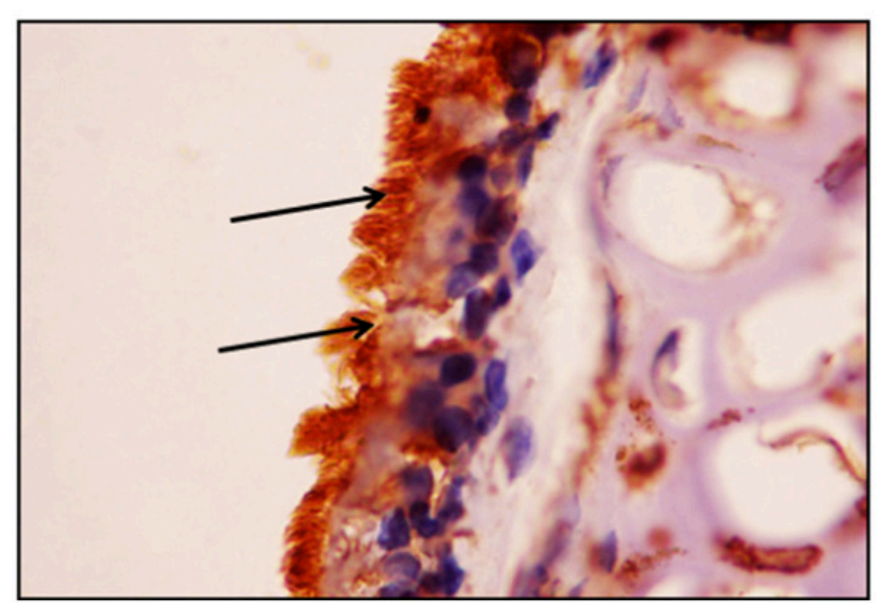

FIGURE 2 - Positive immunoreactivity (arrows) to survivin in tracheal epithelial cytoplasm from alcohol + tobacco animal group ( $\mathrm{x} 400$ magnification).

\section{Apoptotic index (TUNEL reaction)}

These variable results are listed in Table 3. It might be noticed that the tracheal apoptotic index in cigarette smoke group was higher than the control group. The bronchiolar apoptotic index in animals from both groups exposed to tobacco smoke was also above the average control group and at the alveolar level, the cigarette smoke + alcohol group was also higher than the average of the control group. Figures 3 to 6 represent apoptotic cells in respective tissues: trachea, bronchioles, vessels and alveoli. 
TABLE 3 - Statistical analysis of apoptotic index distribution (TUNEL reaction: TdT-mediated dUTP-digoxigenin nick-end labeling) in respiratory tissues of four studied animals groups.

\begin{tabular}{|c|c|c|c|c|}
\hline $\begin{array}{l}\text { Apoptotic index } \\
\text { (TUNEL reaction) }\end{array}$ & Groups & Mean \pm Sd & Minimum & Maximum \\
\hline \multirow{5}{*}{ Trachea } & Control & $0.001 \pm 0.001(\mathrm{~b})$ & 0.00 & 0.01 \\
\hline & Alcohol & $0.005 \pm 0.005(\mathrm{ab})$ & 0.00 & 0.01 \\
\hline & Tobbaco & $0.010 \pm 0.008(a)$ & 0.00 & 0.03 \\
\hline & Alcohol + Tobbaco & $0.006 \pm 0.002(\mathrm{ab})$ & 0.00 & 0.01 \\
\hline & Control & $0.012 \pm 0.0121(b)$ & 0.00 & 0.03 \\
\hline \multirow{3}{*}{ Bronchioles } & Alcohol & $0.023 \pm 0.0329(\mathrm{ab})$ & 0.00 & 0.09 \\
\hline & Tobbaco & $0.062 \pm 0.0326(\mathrm{a})$ & 0.01 & 0.10 \\
\hline & Alcohol + Tobbaco & $0.054 \pm 0.0236(\mathrm{a})$ & 0.03 & 0.08 \\
\hline \multirow{4}{*}{ Vessels } & Control & $0.011 \pm 0.012$ & 0.00 & 0.04 \\
\hline & Alcohol & $0.023 \pm 0.029$ & 0.00 & 0.07 \\
\hline & Tobbaco & $0.028 \pm 0.024$ & 0.01 & 0.08 \\
\hline & Alcohol + Tobbaco & $0.012 \pm 0.010$ & 0.00 & 0.03 \\
\hline \multirow{4}{*}{ Alveolus } & Control & $0.011 \pm 0.012(\mathrm{~b})$ & 0.00 & 0.04 \\
\hline & Alcohol & $0.025 \pm 0.039(\mathrm{ab})$ & 0.00 & 0.11 \\
\hline & Tobbaco & $0.031 \pm 0.021(\mathrm{ab})$ & 0.01 & 0.07 \\
\hline & Alcohol + Tobbaco & $0.050 \pm 0.023(\mathrm{a})$ & 0.03 & 0.09 \\
\hline
\end{tabular}

Comparisons between groups - ANOVA (Tukey)

Tracheal apoptotic index (TUNEL reaction): C x A: $p=0.443 ; \mathrm{C}$ x T: $\mathrm{p}=0.02 * \mathrm{C} \times \mathrm{AT}: \mathrm{p}=0.358 ; \mathrm{A} \times \mathrm{T}: \mathrm{p}=0.414 ; \mathrm{A} \times \mathrm{AT}: \mathrm{p}=0.999 ; \mathrm{T} \times \mathrm{AT}: \mathrm{p}=0.504$. Bronchiolar apoptotic index (TUNEL reaction): C x A: $p=0.849 ; \mathrm{C} x \mathrm{~T}: \mathrm{p}=0.009^{*} ; \mathrm{C} \times \mathrm{AT}: \mathrm{p}=0.033^{*} ; \mathrm{A} \times \mathrm{T}: \mathrm{p}=0.057 * ; \mathrm{A} \times \mathrm{AT}: \mathrm{p}=0.169 ; \mathrm{T} \times \mathrm{AT}$ : $\mathrm{p}=0.943$. Vessels apoptotic index (TUNEL reaction): $\mathrm{C} \times \mathrm{A}: \mathrm{p}=0.742 ; \mathrm{C} \times \mathrm{T}: \mathrm{p}=0.477 ; \mathrm{C} \times \mathrm{AT}: \mathrm{p}=1 ; \mathrm{A} \times \mathrm{T}: \mathrm{p}=0.970 ; \mathrm{A} \times \mathrm{AT}: \mathrm{p}=0.757$; T $\mathrm{x}$ AT: $\mathrm{p}=0.491$. Alveolar apoptotic index (TUNEL reaction): C $\mathrm{x}$ $\mathrm{A}: \mathrm{p}=0.762 ; \mathrm{C} \times \mathrm{T}: \mathrm{p}=0.482 ; \mathrm{C} \times \mathrm{AT}: \mathrm{p}=0.043^{*} ; \mathrm{A} \times \mathrm{T}: \mathrm{p}=0.965 ; \mathrm{A} \times \mathrm{AT}: \mathrm{p}=0.276 ; \mathrm{T} \times \mathrm{AT}: \mathrm{p}=0.524$.
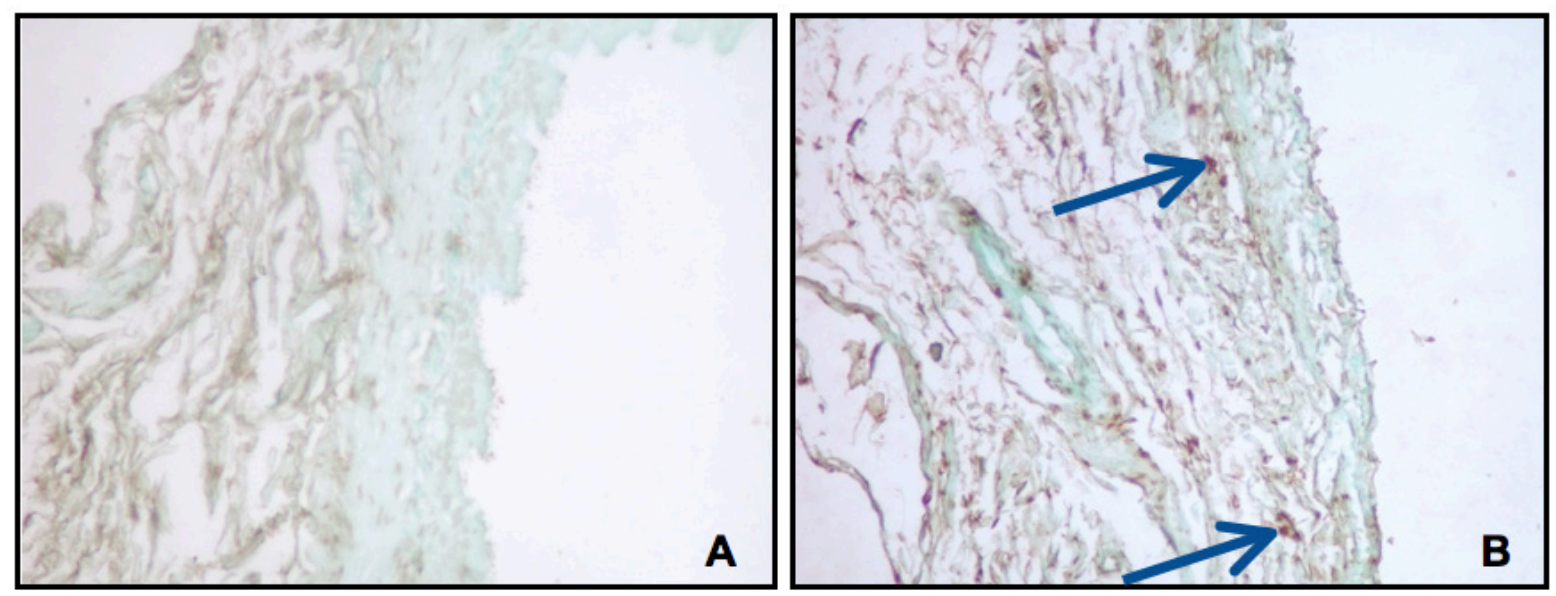

FIGURE 3 - Analysis pictures of tracheal apoptosis by TUNEL technique. A: note apoptosis absence in trachea of a control group animal. B: note the presence of positive cells for apoptosis (arrows) in an animal tobacco group (x400 magnification).

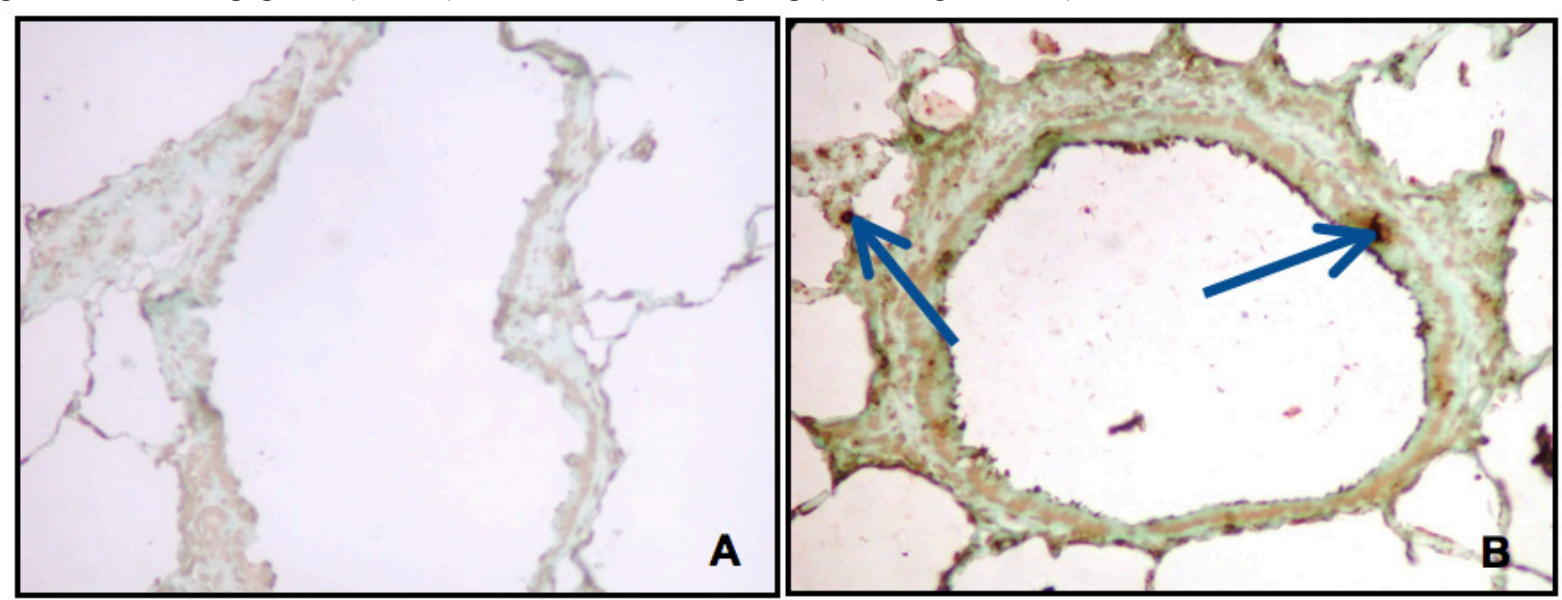

FIGURE 4 - Pictures analysis of bronchioles apoptosis level by the TUNEL technique. A: note the apoptosis absence in the bronchioles of a control group. B: note the presence of cells positive for apoptosis (arrows) in an animal tobacco group (x400 magnification). 

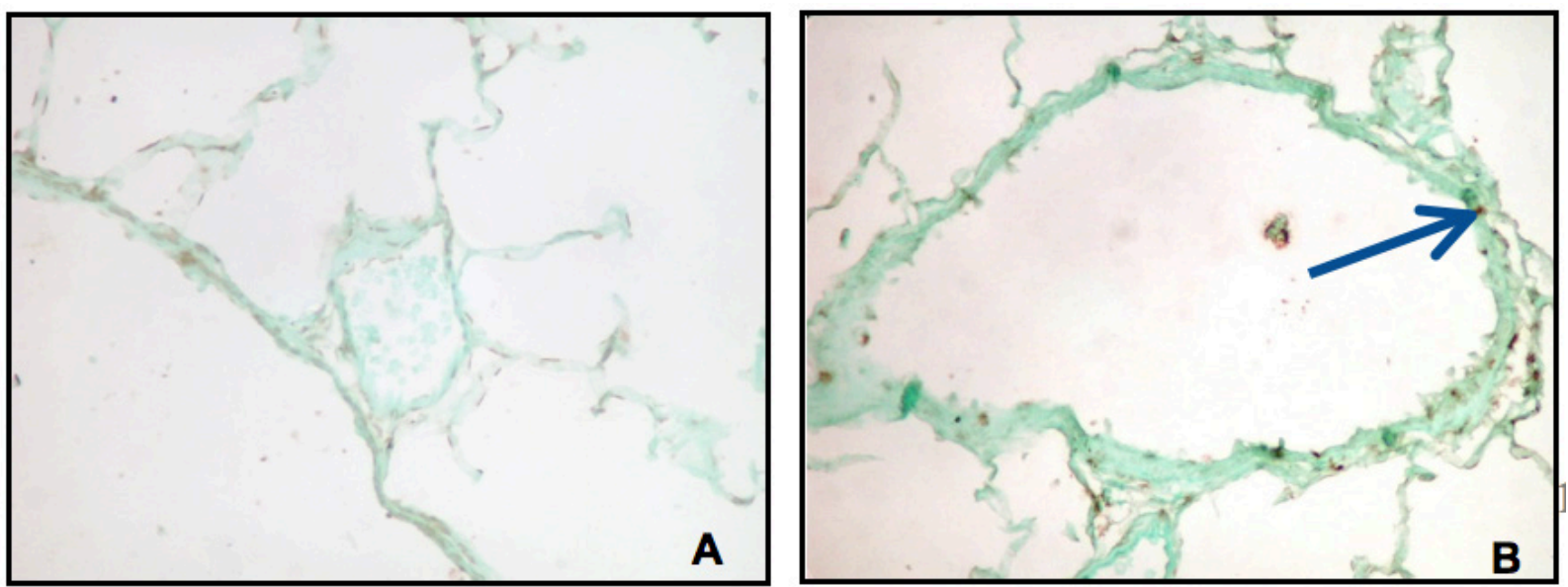

FIGURE 5 - Pictures of the apoptosis analysis in vascular pulmonary by the TUNEL technique. A: note the absence of vascular apoptosis of a control group animal. B: note the presence of positive cells for apoptosis (arrows) in an animal tobacco group (x400 magnification).

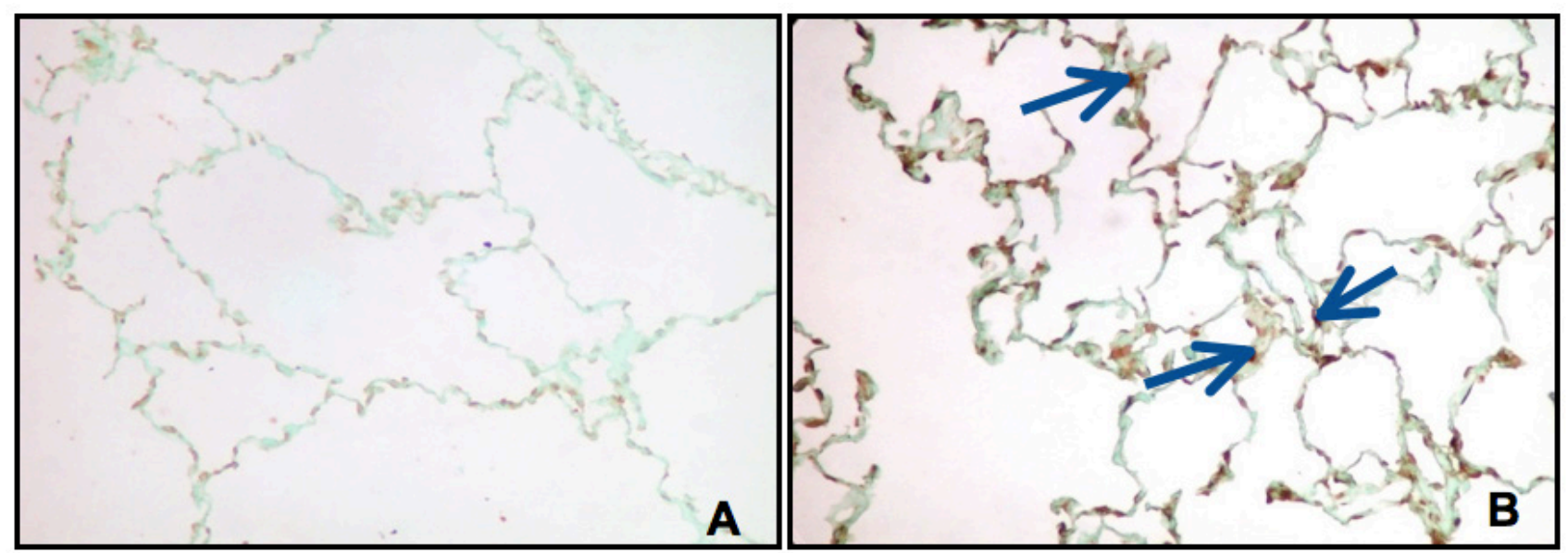

FIGURE 6 - Pictures of the alveolar apoptosis analysis by the TUNEL technique. A: note the absence of alveolar apoptosis in a control group animal. B: note the presence of cells positive for apoptosis (arrows) in an animal alcohol + tobacco group (x400 magnification).

\section{Discussion}

Animalsgrowth

In the present research, it was clearly observed that the associated exposure to cigarette smoke and alcohol contributed to the animal growth impairment. The relation between smoking and body weight has been established in several well-designed studies. The cigarette effect on body weight seems to be mediated by nicotine. Animal experimental studies indicate that cigarette administration induces reduction in body weight, probably as a result of appetite suppression due to acute neurotransmitters elevation (dopamine and serotonin). In humans, smoking increases adrenergic activity, which induces thermogenesis and consequent body weight reduction. Another aspect to consider is that nicotine has a direct effect on adipose tissue metabolism, causing a higher lipid oxidation compared to nonsmokers, which helps us to explain why smokers have lower BMI compared to nonsmokers. In the studied animals we could not demonstrate a reduction in BMI in the ones exposed to tobacco, but in those exposed to alcohol.

In terms of caloric content, ethanol is the only drug whose oxidation by dehydrogenized produces $7.1 \mathrm{kcal}$ per gram of oxidized ethanol. This body energy supply causes reduction in the need to feed, which may have occurred in our animals, explaining both the difficulty of weight gain as well as to achieve a BMI in animals exposed to this drug. In addition to the known toxic ethanol effects on essential nutrients synthesis and absorption? some metabolic abnormalities are also described.

Experimental studies are consistent in reporting a body weight reduction in rats exposed to ethanol ${ }^{10}$. Low ethanol concentrations $5 \%(\mathrm{v} / \mathrm{v})$ as high concentrations $40 \%(\mathrm{v} / \mathrm{v})$ were associated with lower weight gain ${ }^{11}$. According to the results obtained in present research, it was clearly demonstrated that 
both, cigarette smoke and alcohol, interfered negatively in studied animal growth. If such results could be translated to humans, it is important to emphasize the prohibition of alcohol and tobacco consumption for growing children and/or adolescents.

\section{Immunohistochemical study}

\section{Apoptotic index}

Regarding to the immunohistochemical changes in respiratory tissues, cigarette smoke exposure effects or its association to alcohol were highlighted since the tracheal apoptotic index was higher in animals exposed to tobacco and in the association of alcohol + tobacco in the alveoli and bronchioles.

Cancer development is associated to the changes accumulation that occur spontaneously or by induction either in the structure or expression of certain genes. These genetic mutations occur continuously and are repaired by cellular defense mechanism that controls growth, latency and apoptosis. The presence of defense mechanism failures, inherited or generated by mutations, enables resistant clone cell reproduction to the latency phase induction, or apoptosis and to growth control, which may lead to cancer development.

Alveolar wall cells apoptosis (epithelial and endothelial cells) has been described as one of the pathophysiological mechanisms involved in emphysema. Experimental studies suggest caspases involvement, vascular endothelial growth factor deficiency, oxidants, ceramide, CD8 + T cells, elastase and interferon-gamma in alveolar wall cells apoptosis induction.

Moreover, an apoptotic cells clearance default in lungs of patients with emphysema can promote inflammation. In part, this is a result of secondary necrosis and proteases and presence of other pro-inflammatory components. Despite the fact that recognition of apoptotic cells directly induces phagocytes to produce specialized or not anti-inflammatory mediators, this mechanism might be compromised and results in an increased release of pro-inflammatory molecules such as tumor necrosis factor, interleukin-1, interleukin -6 and interleukin-8.

Relating to lung architecture maintenance, alveolar wall cells loss resulting in apoptosis must be compensated by the proliferation of remaining alveolar cells. Imai et al..$^{12}$ found high levels of apoptosis and cell proliferation (PCNA) in alveolar epithelial cells in patients with emphysema.

Regarding the association of alcohol consumption and the apoptosis mechanisms involved, most studies related the chronic alcohol consumption to oxidative stress and apoptotic hepatocyte injury. Studies that associate alcohol, apoptosis and lung tissue are related to pathophysiological mechanism and treatment of acute respiratory distress syndrome ${ }^{3,4}$. In septic patients, chronic and heavy alcohol consumption increases the acute respiratory distress syndrome incidence, a syndrome that requires the alveolar type II cells proliferation and differentiation to repair the alveolar epithelial injury ${ }^{3,4}$

\section{$\underline{\mathrm{P} 53}$}

Negative expressions of P53 and survivin in the lung parenchyma may indicate that despite the increasing of apoptotic index in associated with exposure to cigarette smoke or in combination with alcohol, carcinogenesis has not occurred yet. Immunohistochemical expression of P53 protein, usually occurs due to its accumulation because of p53 gene mutation, with consequent loss of its tumor-suppressing function ${ }^{13}$. Mutation mechanism is controversial, and studies indicate that the protein P53 participates in apoptosis, acting contrary to Bcl-2. Mutations in p53 gene are the most frequent genetic alterations in lung cancer. More than $50 \%$ of malignant tumors have a mutation in p53 allele and loss of the other. These mutations may be due to genetic or environmental factors (such as diet, pollution and smoking).

\section{$\underline{\text { Survivin }}$}

For literature, studies involving lungs and survivin mainly refer to cancers that are already installed. Some studies investigated the correlation between their expressions with positive prognosis / staging or results of treatment of such diseases.

Despite the lack of survivin expression in lung tissue of animals studied in this research, two studies that showed the survivin expression in healthy smokers were found ${ }^{14,15}$. It has been recently described a hypothesis for pulmonary carcinogenesis that emphasizes the inflammation participation as a possible trigger for epithelial-mesenchymal transition and cancer development, the main factor involved is nicotine in cigarettes. Cyclooxygenase and survivin, a factor of resistance to apoptosis and dependent on COX-2, seem to play a key role in this hypothesis. Recent studies have shown that COX-2 promotes cell survival by modulating survivin ${ }^{16}$, which blocks the caspases action, preventing apoptosis. Survivin overexpression is common in different tumor types and shows high levels in plasma $^{17}$, transbronchial biopsy and sputum, and pleural fluid in patients with non-small cell lung cancer ${ }^{18}$.

Immunohistochemical changes in trachea were also more evident in animals exposed to tobacco smoke groups, which showed survivin positive expression despite P53 negative expression. According to Carpagnano et al. ${ }^{14}$, survivin expression 
is closely related to tobacco exposure that promotes inflammation and may be involved with an evolution to a carcinogenic process. Bronchial epithelium survivin expression is an early and crucial event in tumorigenesis induced by tobacco. Thus, it could be suggested that in the animals studied in present study, the exposure to cigarette smoke resulted in more aggressive trachea damages, compared to lung tissue.

This result becomes very relevant since current researches have focused efforts on survivin positive expression identification as an evolution key point for carcinogenesis, thus its early detection could help to prevent a future irreversible event ${ }^{14}$.

\section{Conclusions}

This experimental model resulted in immunohistochemical changes caused mainly by exposure to cigarette smoke. Synergism between alcohol and tobacco was evident in the growth retardation in animal and cellular apoptotic index. As a contribution to clinical research this study showed that positive tracheal immunoexpression for survivin in animals exposed to tobacco smoke, alone or in combination with alcohol, with negative immunostaining for P53, may represent early detection of a future carcinogenesis development.

\section{References}

1. Magnani KL, Cataneo DC, Capelozzi VL, Defaveri J, Hasimoto EN, Cataneo AJM. Lung morphology and growth of rats exposed to tobacco smoke and alcohol. Acta Cir Bras. 2012;7(10):687-93. doi 10.1590/S0102-86502012001000004.

2. Reed JC. The Survivin saga goes in vivo. J Clin Invest. 2001;108:9659. doi: 10.1172/JCI14123.

3. Guidot DM, Hart CM. Alcohol abuse and acute lung injury: epidemiology and pathophysiology of a recetly recognized association. J Investig Med. 2005;53:235-45. doi: 10.2310/6650.2005.53506.

4. Wakabayashi I, Kato H. Alcohol abuse as a risk factor for ARDS. Nihon Arukoru Yakubutsu Igakkai Zasshi. 2006;41:400-6. PMID: 17176845

5. Paiva SAR, Zornoff LAM, Okoshi MP, Okoshi MP, Okoshi K, Cicoga AC, Campana AO. Comportamento de variáveis cardíacas em animais expostos à fumaça de cigarro. Arq Bras Cardiol. 2003;81:221-4.

6. Hsu SM, Raine L, Fanger H. Use of avidin-biotin-peroxidase complex $(\mathrm{ABC})$ in peroxidase techniques: a comparasion betweem $\mathrm{ABC}$ and unlabeled antibody (PAP) procedures. J Histochem Cytochem. 1981;29:577-80. doi: 10.1177/29.4.6166661.

7. Gavrieli Y, Sherman Y, Ben-Sasson SA. Identification of programmed cell death in situ via specific labeling of nuclear DNA fragmentation. J Cell Biol. 1992;119:493-501. PMID: 1400587.

8. Chen H, Vlahos R, Bozinovski S, Jones J, Anderson GP, Morris MJ. Effect of short-term cigarette smoke exposure on body weight, appetite and brain neuropeptide $\mathrm{Y}$ in mice. Neuropsychopharmacology. 2005;30:713-9. doi: 10.1038/sj.npp.1300597.
9. Lieber CS. Perspectives: do alcohol calories count? Am J Clin Nutr. 1991;54:976-82. PMID: 1957830.

10. Pereira RSC, Hasimoto CN, Pelafsky L, Llanos JC, Cataneo DC, Spadella CT, Minossi JG. Intestinal healing in rats submitted to ethanol ingestion. Acta Cir Bras. 2012;27:236-43. doi: 10.1590/ S0102-86502012000300006.

11. Macieira MS, Almeida WG, Silva EA, Schenberg LC, NakamuraPalacios EM. Alcohol dependence induced in rats by semivoluntary intermittent intake. Braz J Med Biol Res. 1997;30:1107-11. PMID: 9458971.

12. Imai K, Mercer BA, Schulman LL, Sonett JR, D'Armiento JM. Correlation of lung surface area to apoptosis and proliferation in human emphysema. Eur Respir J. 2005;25:250-8. doi: 10.1183/09031936.05.00023704.

13. Shaw PH. The role of P53 in cell cycle regulation. Pathol Res Pract. 1996;192:669-75. doi: 10.1016/S0344-0338(96)80088-4.

14. Carpagnano GE, Spanevello A, Palladino GP, Gramiccioni C, Ruggieri C, Carpagnano F, Foschino Barbaro MP. Cigarette smoke and increased COX-2 and survivin levels in exhaled breath condensate of lung cancer patients: how hot is the link? Lung Cancer. 2009;67:108-13. doi: 10.1016/j.lungcan.2009.03.033.

15. Jin Q, Menter DG, Mao L, Hong WK, Lee HY. Survivin expression in normal human bronchial epithelial cells: an early and critical step in tumorigenesis induced by tobacco exposure. Carcinogenesis. 2008; 29:1614-22. doi: 10.1093/carcin/bgm234.

16. Krysan K, Dalwadi H, Sharma S, Pòld M, Dubinett $S$. Cyclooxygenase 2-dependent expression of survivin is critical for apoptosis resistance in non-small cell lung cancer. Cancer Res. 2004;64:6359-62. doi: 10.1158/0008-5472.CAN-04-1681.

17. Derin D, Sodinç HO, Guney N, Tas F, Camlica H, Duranyildiz D, Yasasever V, Topuz E. Serum levels of apoptosis biomarkers, survivin and TNF-alpha in nonsmall cell lung cancer. Lung Cancer. 2008;59:240-5. doi: 10.1016/j.lungcan.2007.08.005.

18. Dong DQ, Yang YH, Xue DY, Feng XJ. Expression of survivin mRNA of sputum and pleural effusions in human lung cancer. Zhong Nan Da Xue Xue Bao Yi Xue Ban. 2006;31(6):848-52. PMID: 17213581.

\section{Correspondence:}

Antônio José Maria Cataneo

Programa de Pós-Graduação em Bases Gerais da Cirurgia

Faculdade de Medicina de Botucatu, UNESP

18618-970 São Paulo - SP Brasil

Tel.: (55 14)9775-3452

Fax: (55 14)3815-7615

acataneo@fmb.unesp.br

Received: Nov 12, 2014

Review: Jan 14, 2015

Accepted: Feb 13, 2015

Conflict of interest: none

Financial source: Sao Paulo Research Foundation (FAPESP)

${ }^{1}$ Research performed at Experimental Laboratory of Surgery, Botucatu School of Medicine, Sao Paulo State University (UNESP), Brazil. Part of PhD degree thesis, Postgraduate Program in General Basis of Surgery, UNESP. Tutor: Antonio Jose Maria Cataneo. Co-Tutor: Daniele Cristina Cataneo. 